\title{
Physiological Water Immersion Induced Hand Wrinkling in Medical Students
}

\author{
Ravindran Surya*, Antony Jason Augustine, Ankith K and Sebastian Criton \\ Departments of Dermatology, Amala institute of medical sciences, Thrissur, India
}

Submission: February 12, 2020; Published: February 21, 2020

*Corresponding author: Ravindran Surya, Department of Dermatology, Amala institute of medical sciences Thrissur, India

Abstract

Aim: This study aims to observe if there is a physiological variation in the appearance or disappearance of water immersion induced wrinkling time in medical students.

Introduction: Skin wrinkling is hypothesized as an adaptive phenomenon that is generated as an evolutionary process. Water immersion induced wrinkling is a non-invasive test graded from 0-5 that involves placing one's hands into lukewarm water for a set amount of time. Despite the increased interest in skin rejuvenation, a baseline study describing the variation in water immersion induced hand wrinkling is still missing.

Objectives: To induce Wrinkling in patients with Dermatoses under standard conditions. To assess the water immersion induced wrinkling in normal population

Methods: This is an observational study done in 80 medical students who attended dermatology posting at the department of Dermatology in Amala Institute of Medical Sciences for a period of ten months. The subject's both hands were placed in tap water for to elicit wrinkling. The data was analyzed using statistical methods: Student's unpaired $t$ test, ANOVA test, Kruskal Wallis test.

Results: Out of 80 students females' participants took longer to develop water immersion induced wrinkles compared to males.

Conclusion: There is a significant variation in the wrinkling pattern with respect to gender. The role of estrogen was a novel observation.

Keywords: Water Induced Wrinkling Time; Wrinkling; Hand Wrinkling; Vasoconstriction; Estrogen; Hand Dermatitis

\section{Introduction}

Skin wrinkling on immersion in water is hypothesized as an adaptive phenomenon that is generated as an evolutionary process [1]. The exact mechanism of wrinkling is unknown. It may be postulated that during the course of ageing skin gets transformed in terms of structural composition, structural organization, size and properties. Water immersion induced wrinkling is related to increased skin rigidity of stratum corneum coupled with weakening and loss of echogenicity of upper dermis [2].On exposure to water the skin of fingers and toes wrinkle which was initially attributed to local osmotic reactions [3]. Despite the increased interest in skin rejuvenation, a baseline study describing the demographic variation in hand wrinkling is still missing. In the current study, we aim to experimentally assess the physiological hand wrinkling time in medical students.

\section{Methodology}

All consenting medical students attending the Dermatology posting in the Dermatology department of Amala Institute of Medical Sciences, Thrissur from July 2017 to December 2017 were first evaluated on the basis of demographic data and comorbidities using a Performa by the investigator. Wrinkling was induced by immersing both hands of the subject in $3 \mathrm{~L}$ of $28 \mathrm{C}$ tap water obtained from a common source. The experiment was carried at a standard room temperature of $25^{\circ} \mathrm{C}$ and water was obtained from a common source and filled in a $60^{*} 49 \mathrm{~cm}$ plastic trough. The participants were asked to submerge their hands in water for a sustained period until they noticed the first appearance of wrinkling. Photographic evaluation before and after inducing wrinkling was taken in consenting participants. Following this the time of early 
disappearance and complete disappearance of wrinkles was noted. All data were analyzed using the Statistical Package for Social Sciences (SPSS) software, version 22 , and $\mathrm{P}$ values $\leq 0.05$ were considered statistically significant. Means, medians, and standard deviations were utilized to summarize the responses as measures of central tendency. Associations between baseline variables and outcomes were determined using Student's unpaired t test, ANOVA test.

\section{Results}

Eighty medical students, 61 females and 19 males, were enrolled in the study in from July 2017 to December 2017 .The youngest participant was 19 years old and the oldest one was aged 23 years (mean age is 20.76 years). The majority of participants were in the age group of 20 to 22 years. There were three students aged less than 20 years. The minimum and maximum time taken for hand wrinkling to appear in females was 12 minutes 16 seconds and 34 minutes and 28 seconds respectively. (Mean= $16.2+8.9$ ). The minimum and maximum time taken for hand wrinkling to appear in males was 2 minutes and 36 minutes and 20 seconds respectively. (Mean=12.4+-9.4). The average time taken for first disappearance of hand wrinkling was more in Females compared to males (Mean=3.0447/ 3.5767). The average time taken for final disappearance of hand wrinkling was more in Females compared to males (Mean=8.41118.9497/). With regard to co-morbidities those participants who had contact dermatitis on their hands developed had an earlier wrinkling appearance (10 minutes 3 seconds) compared to those without co-morbidities. (13min 4 seconds). On the contrast participants with Contact dermatitis with scaly erythematous plaques showed an earlier appearance and later disappearance of wrinkling (6.2 seconds) compared to those without co-morbidities (9minutes).

\section{Discussion}

Wrinkling on exposure to water is a temporary phenomenon and is referred to as pruney fingers or water aging. Previous studies demonstrated that appearance of wrinkles depends on many factors like age, temperature of water, water hardness, $\mathrm{pH}$ etc. In our study we found a demographic variation with regards to sex and time of appearance of wrinkles by maintain other parameters constant. On an average we found male participants (12.4secs) developed wrinkling earlier compared to female participants. (16.2secs). The mechanism of wrinkling is still unknown. Our study showed that females took longer time compared to males to develop water immersion induced wrinkling. It is known that a state of hypoestrogenism during menopause is known to accelerate age-related deterioration, which results in thinner skin, and an increase in number and depth of wrinkles [4]. Hormone replacement therapy (HRT) has been shown to increase epidermal hydration, skin elasticity, and also reduces skin wrinkles [5]. Hence it may be postulated that males with low estrogen content took less time to develop water immersion induced wrinkling. However future studies are needed to confirm our hypothesis (Table 1).

Table 1: Comparison of sex with wrinkling time.

\begin{tabular}{|c|c|c|c|c|c|}
\hline & Sex & N & Mean & Std. Deviation & P value \\
\hline \multirow{2}{*}{ Time of Appearance } & M & 19 & 12.4192 & 8.65984 & 9.42425 \\
\cline { 2 - 6 } & F & 61 & 16.2916 & 1.58201 & 0.903 \\
\hline \multirow{2}{*}{ Time of First Disappearance } & M & 19 & 3.0447 & 3.32816 & 4.90932 \\
\cline { 2 - 6 } Time of Complete Disappearance & F & 61 & 3.5767 & 5.73815 & 0.181 \\
\hline \multirow{2}{*}{ Interval Time } & M & 19 & 8.4111 & 4.8822 & 4.78917 \\
\hline
\end{tabular}

Table 2: Comparison of co-morbid illness with wrinkling time.

\begin{tabular}{|c|c|c|c|c|}
\hline & Comorbid Illness & N & Mean & Std. Deviation \\
\hline \multirow{2}{*}{ Time of Appearance } & 0 & 78 & 13.4165 & 9.43959 \\
\cline { 2 - 5 } & 1 & 2 & 10.31 & 4.01637 \\
\hline \multirow{2}{*}{ Time of First Disappearearance } & 0 & 78 & 3.4751 & 3.04049 \\
\cline { 2 - 5 } & 1 & 2 & 2.485 & 0.0495 \\
\hline \multirow{2}{*}{ Time of Complete Disappearance } & 0 & 78 & 8.8886 & 5.57398 \\
\cline { 2 - 5 } & 1 & 78 & 5.2413 & 2.70822 \\
\hline \multirow{2}{*}{ Interval Time } & 0 & 2 & 3.83 & 4.82157 \\
\hline
\end{tabular}


It was earlier postulated that when water gets absorbed into the keratin content of skin it expands to a larger surface area causing it to fold creating wrinkling lines. However, it was in 1935 Lewis \& Pickering et al. [6] that studied patients with median nerve palsy and uncovered that wrinkling spared the areas innervated by a damaged nerve thus postulating that there is a role of nervous system in wrinkling phenomenon. This theory was supported by many others in subsequent years [7-14]. Vasudevan [14] et al. demonstrated that that by blocking the sympathetic response, either temporarily via lumbar epidural infusion or permanently via chemical or surgical cervical sympathectomy, terminated wetwrinkling response. Cales \& Weber [3] in 1997 proposed that fingers and toes wrinkle if soaked in water for around five minutes and attributed the same to local osmotic reactions. Wilder-Smith et al. [15] hypothesized that that the finger-wrinkling mechanism may be due to digit pulp vasoconstriction and wrinkles can be induced by vasoconstrictive agents [16] (Table 2).

Table 3: Time taken for appearance of wrinkling and disappearance of water immersion induced wrinkling.

\begin{tabular}{|c|c|c|c|c|c|}
\hline & N & Minimum & Maximum & Mean & Std. Deviation \\
\hline \multirow{2}{*}{ Time of Appearance } & 19 & 6.16 & 34.28 & 16.2916 & 8.65984 \\
\cline { 2 - 6 } & 61 & 2.04 & 36.2 & 12.4192 & 9.42425 \\
\hline \multirow{2}{*}{ Time of First Disappearearance } & 19 & 1.2 & 6.24 & 3.0447 & 1.58201 \\
\cline { 2 - 6 } & 61 & 0.52 & 24.1 & 3.5767 & 3.32816 \\
\hline \multirow{2}{*}{ Time of Complete Disappearance } & 19 & 2.27 & 24.14 & 8.4111 & 8.90932 \\
\cline { 2 - 6 } & 61 & 1.55 & 27.1 & 5.1568 & 4.73815 \\
\hline \multirow{2}{*}{ Interval Time } & 19 & 0.52 & 21.3 & 5.2213 & 4.78917 \\
\cline { 2 - 6 } & 61 & 0.09 & & & 4.822 \\
\hline
\end{tabular}

Participants who had dermatoses like contact dermatitis on their hands and was subjected to the study showed an earlier appearance and later disappearance of wrinkling compared to those without co-morbidities. Even though the reason of this early wrinkling time is unclear it can be postulated that these chronic dermatoses might have altered the water binding capacity of keratins. A similar mechanism is associated with aquagenic wrinkling of palms (AWP) which is characterized by a rapid formation of wrinkles upon limited exposure to water i.e as early as 2 minutes. The pathomechanism of this entity is due to an increase in the water-binding capacity of keratins, mediated by increased salt concentrations in the epidermis [17]. Infants with marasmus, a form of protein-energy malnutrition, also may have elevated sweat chloride concentrations [18] and have been observed to have excessive skin wrinkling similar to that seen in patients with Cystic Fibrosis [19-20]. Wrinkling of palms and soles after immersion to water may be an evolutionary adaptation. But it is debatable at present whether the wrinkling of skin evolved in our ancestors to support walking in wet conditions or to enable better gripping of wet objects [21] (Table 3).

\section{Conclusion}

Water immersion induced wrinkling is a physiological phenomenon yet shows a demographic variation. The pathogenesis of wrinkling remains unknown and more studies are warranted to assess whether it varies with different dermatoses and the influence of estrogen in its formation. Our study showed that with respect to gender females exhibited more time to develop water immersion induced wrinkling compared to males hinting the role of estrogen in the same.

\section{Limitations of study}

i. Single observer study: Observer bias.

ii. The diurnal variation in the development of water immersion induced wrinkling was not tested for, owing to circadian variations observed in autonomic nervous system functioning.

iii. Constancy of environmental factors and hardness of water was not considered.

\section{Acknowledgment}

The authors are very grateful to Mrs Jini MP and Mr Vidhu for their statistical help.

\section{References}

1. Kareklas K, Nettle D, Smulders TV (2013) Water-induced finger wrinkles improve handling of wet objects. Biol Lett 9(2): 20120999.

2. Yin J, Gerling GJ, Chen X (2010) Mechanical modeling of a wrinkled fingertip immersed in water. Acta Biomater 6(4): 1487-1496.

3. Cales L, Weber RA (1997) Effects of water temperature on skin wrinkling. Journal of Hand Surgery 22(4): 747-749.

4. Stevenson S, Thornton J (2007) Effect of estrogens on skin aging and the potential role of SERMs. Clinical Interventions in Aging 2(3): 283297

5. Phillips TJ, Demircay Z, Sahu M (2001) Hormonal effects on skin aging. Clin. Geriatr Med 17(4): 661-672.

6. Lewis T, Pickering GW (1936) Circulatory changes in fingers in some diseases of the nervous system, with special reference to digital atrophy of peripheral nerve lesions. Clin Sci 2: 149. 
7. ORiain S (1973) A new and simple test of nerve function in hand. Br Med J 3(5881): 615-616.

8. Bull C, Henry JA (1977): Finger wrinkling: a test of autonomic function Br Med J 1(6060): 551-552.

9. Braham J, Sadeh M, Saravoa Pinhas I (1979) Skin wrinkling on immersion of hands: a test of sympathetic function. Arch Neurol 36(2): 113-114.

10. Alvarez G, Eurolo J, Canales P (1980) Finger wrinkling after immersion in water. Br Med J 281(6240): 585-586.

11. Vasudevan TM, Van Ru AM, Nukada H, Taylor PK (2000): Skin wrinkling for the assessment of sympathetic function in the limbs. Aust NZ J Surg 70(1): 57-59.

12. Hsieh CH, Huang KF, Liliang PC, Jeng SF, Tsai HH (2006) Paradoxical response to water immersion in replanted fingers. Clin Auton Res 16(3): 223-227.

13. Hsieh CH, Huang KF, Liliang PC, Huang PC, Shih HM, Rau CS (2007) EMLA and water immersion cause similar vasodilatation in replanted fingers. J Surg Res 143(2): 265-269.

14. Tindall A, Dawood R, Povlsen B (2006) Case of the month: the skin wrinkle test - a simple nerve injury test for paediatric and uncooperative patients. Emerg Med J 23(11): 883-886.
15. Wilder Smith EP (2004) Water immersion wrinkling: physiology and use as an indicator of sympathetic function. Clin Auton Res 14(2): 125131.

16. Wilder Smith EP, Chow A (2003a) Water immersion and EMLA cause similar digit skin wrinkling and vasoconstriction. Microvasc Res 66(1): 68-72.

17. Moynahan EJ (1974) Letter: Skin wrinkling in cystic fibrosis. Lancet 2(7886): 953

18. Yigit HSelimoglu MA Altinkaynak S(2003) Sweat test results in children with primary protein energy malnutrition J Pediatr Gastroenterol Nutr: 37242-37245.

19. Elliott RB (1974) Letter: Wrinkling of skin in cystic fibrosis. Lancet 2(7872): 108

20. Katz KA, Yan AC, Turner ML (2005) Aquagenic Wrinkling of the Palms in Patients with Cystic Fibrosis Homozygous for the $\Delta$ F508 CFTR Mutation. Arch Dermatol 141(5): 621-624.

21. Yin J, Gerling GJ, Chen X (2010) Mechanical modeling of a wrinkled fingertip immersed in water. Acta Biomater 6(4): 1487-1496.

\section{Your next submission with Juniper Publishers} will reach you the below assets

- Quality Editorial service

- Swift Peer Review

- Reprints availability

- E-prints Service

- Manuscript Podcast for convenient understanding

- Global attainment for your research

- Manuscript accessibility in different formats

( Pdf, E-pub, Full Text, Audio)

- Unceasing customer service

Track the below URL for one-step submission

https://juniperpublishers.com/online-submission.php 